\title{
Editorial for the special issue
}

\section{What is New in Perception-Action and Memory-Attention}

\author{
Daniel Mograbi ${ }^{1,2}$ and José Aparecido Da Silva ${ }^{3}$ \\ 1- Pontifícia Universidade Católica do Rio de Janeiro, Rio de Janeiro, RJ, Brazil \\ 2- King's College London, London, United Kingdom \\ 3- Universidade de São Paulo, Ribeirão Preto, SP, Brazil
}

On September 27 and 28, 2013, we held the "Attention, Perception and Memory" symposium at the University of São Paulo campus in Ribeirão Preto, which brought together studies and research relevant to these fields. Specialists from Brazil and other countries were invited to participate in the symposium, allowing us to share not only ideas but also results and suggestions for sufficiently sound and relevant future projects to update this area and meet the recommendations made by the country's research funding agencies regarding the internationalization of Brazilian research. Another objective of the symposium was to pay homage to the late Prof. Nilton P. Ribeiro-Filho from the Federal University of Rio de Janeiro, a brilliant professor, dear colleague and friend, and one of the greatest enthusiasts of research in Perception and Psychophysics who shared with us over 40 years of experience in teaching and research. Upon receiving the news that the symposium would be dedicated to the memory of Prof. RibeiroFilho, a number of participants promptly acknowledged the importance of such a tribute. Prof. J. LandeiraFernandez, Editor-in-Chief of the journal Psychology \& Neuroscience, immediately contacted us and suggested inviting the presenters of the symposium to create a special issue of the journal dedicated to the memory of Prof. Ribeiro-Filho, with whom he also shared several years of work and research. Pleased to receive the request and after receiving the call for papers, the invitees returned almost two dozen manuscripts, of which 19 were accepted for publication after peer review. Grouped into two subareas-Perception-Action and Memory-
Attention - readers of Psychology \& Neuroscience will observe that the works cover a wide range of topics, from Spatial Perception and False Memory to Human Locomotion, Postural Control, Working Memory, Pain Measurement, Alzheimer's Disease, and Visual Attention. Revisiting William James, the father of American pragmatism, who asserted that man is not granted all truth and wisdom because both depend on the vantage point from which one views the world, the articles that comprise this special issue exhibit the same perspicacity, presenting an outline of the broad range of current knowledge in the respective fields. The abundance of studies undertaken within these areas has led to the creation of specialized journals that focus on specific themes. We are grateful to all of the authors who promptly accepted our invitation to participate in the symposium and devoted their valuable time to writing the articles published herein. Special thanks go to Prof. Landeira-Fernandez, whose hawk-eyed vision and acute intelligence ensured that the presentation of these studies went beyond a simple symposium program and whose perseverance in compiling this volume culminated in its fruition. We hope that this special issue serves as a relevant source of research and knowledge for undergraduate and postgraduate students, specialists in the area and others who are interested in the basic psychological processes that are presented. We also hope that this special issue contributes to the insertion of the studies performed in this area by Brazilians in the international arena, thus meeting one of the institutional goals of our academy. 